panacea, but panaceas were still respectable. In his arguments he used the best available medical knowledge. These arguments were much better than those for the Brunonian system of therapy, which had some professional support later during the eighteenth century, and as good as those for the homœopathic system which enjoyed considerable popularity during the nineteenth century. But his arguments were based on alchemical concepts and are now almost unintelligible. They are interesting, though, because they bring out very clearly the underlying metaphysics, from which alchemy derived its genuine, as apart from its fraudulent, appeal.

This metaphysics is the ancient faith in the Great Chain of Being, a faith practically universal in folklore and prevailing in most Greek philosophy. Even the atomist Lucretius, who should have repudiated it, is strongly tinged with it. It is well summerized in a sentence from one of the early "Hermetic" works which Berkeley quotes. "All parts of the world vegetate by a fine subtle ether, which acts as an engine or instrument, subject to the will of the supreme God". It requires only the further statement, that there is one universal material substrate which this ether informs or transforms, striving to bring into existence more perfect from less perfect forms. Any modern who is shocked by this kind of view should read Newton on natural transformations in Query 30, appended to his "Opticks". He should note that where he differs from Newton and Berkeley is in the metaphysics he uses to order the evidence before him far more than in the evidence itself, which could all be taken in alchemical terms.

Prof. T. E. Jessop provides a useful introduction, in which he disposes of the claim that the thought of "Siris" is inconsistent with Berkeley's earlier works. He has also hunted up the often very obscure references given in the text, and has printed in an appendix the passages in Boerhaave's "Elementa Chemiæ" of which Berkeley makes extensive use. Altogether, it is a volume of which editors and publishers may well feel proud. A. D. RiтонIE

\section{BAND SPECTRA OF DIATOMIC MOLECULES}

Tables de Constantes et Données numériques

5 : Constantes sélectionnées. Atlas des longueurs d'onde caractéristiques des bandes d'émission et d'absorption des molécules diatomiques. Établi par R. F. Barrow, A. D. Caunt, A. R. Downie, R. Herman, E. Huldt, A. McKellar, E. Miescher, B. Rosen et K. Wieland. Pp. 390. (Paris : Hermann et Cie., 1952.) 5600 francs.

GOR atomic spectra, tables of collected measureI ments of lines arranged in order of wave-length are of considerable value for identification ; indeed, books such as Kayser and Ritschl's "Hauptlinien" and Harrison's "M.I.T. Wavelength Tables" are indispensable. There is a natural tendency to attempt a similar project for the banded molecular spectra. However, the problem is different and much more difficult. Whereas individual lines can often be measured with great precision, band spectra are more often observed with rather small dispersion, and the accuracy of measurement is much less. Even with big dispersion, the exact location of the band herds is complicated by the rotational fine structure of the bands, the choice of head position often depending to some extent on the instrument used, the source in which the band is excited and even on the observer. Often, too, there are complications due to overlapping rotational structure from another band. Whereas for atomic spectra each main electronic transition is responsible for a single multiplet of relatively few lines, with molecules each transition leads to a whole band system, and it is usually preferable to try identification of systems rather than of individual bands.

Volume 4 of "Tables de Constantes sélectionnées" was produced in 1951 by the same authors as the present volume, and contained a very useful collection of data of the spectra and molecular constants of individual diatomic molecules. The present volume is essentially a supplement to this, and most of the previously listed bands, with a few more from recent literature, are grouped into one table, containing nearly 13,000 heads of 299 molecules. They cover the wave-length range 15,050-672 A. For each band"the direction of degradation, emitting molecule, electronic transition (where known), vibrational transition, and up to four of the characteristic or strongest bands of the system are listed. No indications are given of the appearance of the band (that is, how many heads), the type of sources in which it may be expected or intensity relative to others of the system. The term "Atlas" should not be translated literally ; there are no photographs or diagrams. The volume also includes wave-length lists, involving 2,500 heads, of bands of $\mathrm{C}_{2}, \mathrm{CH}, \mathrm{CH}^{+}, \mathrm{CN}, \mathrm{CO}$, $\mathrm{CO}^{+}, \mathrm{N}_{2}, \mathrm{~N}_{2}+, \mathrm{NH}, \mathrm{NH}^{+}, \mathrm{NO}, \mathrm{O}_{2}, \mathrm{O}_{2}^{+}, \mathrm{OH}$ and $\mathrm{OH}^{+}$separately; these are mere lists of wavelengths without indication of direction of degradation, system or intensity, and it is difficult to imagine any use for them. The volume also contains a list of about four thousend lines of $\mathrm{H}_{2}$, with their transitions.

It is natural to compare this volume with Pearse and Grydon's "Identification of Molecular Spectra", an earlier attack on the same problem. This also included a much shorter list of principal band heads in order of wave-length, but relied mainly on photographs and individual tables. The present volume has the advantage of including the photographic infra-red and far ultra-violet regions, but the disadvantage that it is strictly limited to diatomic molecules, whereas Pearse and Gaydon included the main triatomic and polyatomic molecules and also gave indications of band appearance and sources in the main list. The much greater size of the table in the volume under review is not necessarily a big advantage. In the main visible and near ultraviolet region there are three or four bands to an angstrom, so that with the normal accuracy of measurement several chance coincidences will inevitably occur for each band head. In many cases the selection of material seems poor. Thus, as examples, about fifty heads of $\mathrm{BaBr}$ are listed around 5400-5150 A., whereas the six main sequence heads should be sufficient ; for the extensive $B \rightarrow X$ system of $\mathrm{Te}_{2}$, about a hundred heads are included. This does not really make identification more certain ; it merely confuses the issue by increasing the number of chance coincidences.

The volume can, of course, only be made use of in conjunction with the previous Vol. 4, and in view of the limited usefulness of tables of this kind, unless supplemented by photographs, the high price would seem to put it in the luxury rather than the utility category. A. G. GAYDON 